\title{
Significações de si: sala de apoio como lugar destinado ao não saber na escola
}

\author{
Luciane Guimarães Batistella Bianchini \\ Universidade Estadual Paulista \\ Francismara Neves de Oliveira \\ Universidade Estadual de Londrina \\ Mário Sérgio Vasconcelos \\ Universidade Estadual Paulista
}

\section{Resumo}

O estudo de natureza qualitativa, modalidade descritivo-interpretativa, apoiou-se no referencial teórico piagetiano para analisar as significações de cinquenta e dois alunos frequentando salas de apoio à aprendizagem. Os resultados indicaram que as significações dos alunos sobre dificuldades de aprendizagem, erro e sala de apoio correspondem a estereótipos, estigmas e inferiorizações de sua condição para atingir os objetivos da aprendizagem. As dificuldades de aprendizagem são vistas como um problema próprio de sua condição pessoal ou familiar enquanto a sala de apoio, um espaço de punição para aqueles que apresentam dificuldades para aprender.

Palavras-chave: Sala de apoio. Dificuldades de aprendizagem. Erro.

\section{Significances of itself: tutoring as a place intended not to knowing at school}

\section{Abstract}

The qualitative study, in its descriptive and interpretive modality, was based on Piaget's theoretical framework in order to analyze the significances of fifty-two students attending classes with tutors. The results indicated that the significances of students about difficulties on learning, errors and tutoring have to do with stereotypes, stigmas and inferiority of their condition to achieve learning objectives. Learning difficulties are seen as a problem of their own personal or family situation, while tutoring a place of punishment for those who have learning difficulties.

Keywords: Tutoring. Learning difficulties. Error. 
Significações de si: sala de apoio como lugar destinado ao não saber na escola

\section{Significaciones de si: clases de apoyo como un lugar destinado al no saber en la escuela}

\section{Resumen}

El estudio de naturaleza cualitativa, modalidad descriptivo-interpretativa, tuvo como base el referencial teórico piagetiano para analizar las significaciones de cincuenta y dos alumnos frecuentando clases de apoyo de aprendizaje. Los resultados indicaron que las significaciones de los alumnos sobre dificultades de aprendizaje, errores y clases de apoyo corresponden a estereotipos, estigmas e inferiorizaciones de su condición para alcanzar sus objetivos de aprendizaje. Las dificultades de aprendizaje son vistas como un problema propio de su condición personal o familiar, mientras que la clase de apoyo un espacio de castigo para aquellos que presentan dificultades para aprender.

Palabras-clave: Clase de apoyo. Dificultad de aprendizaje. Error.

\section{Introdução}

Ao pensarmos nas dificuldades de aprendizagem, é preciso reconhecer que, na complexidade da escola, os processos envolvidos são marcados por trajetórias diferenciadas, que são avaliadas como satisfatórias ou insatisfatórias mediante um padrão de normalidade que permeia o cotidiano escolar. Nessa complexidade, interatuam diferentes expectativas em relação ao domínio dos conteúdos escolares e apreensão do conhecimento. Como lócus de desejos tão complexos, é passível a existência na escola de relações de inadequação, descontinuidade, rotulação e fragmentação. Essas relações coexistem com aquelas valorizadas como assertivas, pedagogicamente corretas, científicas, enfim, adequadas às exigências da demanda escolar.

Representando a própria dificuldade do ser humano em lidar com a complexidade, deparamo-nos no cenário escolar com a dicotomização do aprender. Por um lado, um contexto de demandas e expectativas em torno daquele que "aprende" e, por outro, um cenário de ansiedade e angústia, proporcionado pela ausência de compreensão sobre aquele que ocupa o lugar do não saber ou daquele que apresenta dificuldades para aprender, como se os dois lados indicassem processos distintos. $\bigcirc$ resultado da falta 
de compreensão sobre as dificuldades de aprendizagem tem gerado, na maioria dos casos, estigmas e estereótipos que atingem a família, o aluno, os professores e a escola, produzindo, enfatizando e generalizando condições incapacitantes do aprender.

Pautados na perspectiva teórico-piagetiana, consideramos que o aprender, o não aprender e as dificuldades para aprender são elementos que constituem um processo. Assim, a aprendizagem (processo) engendra múltiplas possibilidades e seu sucesso ou insucesso depende de condições de construção ou (re) construção que não estão localizadas isoladamente no sujeito, ou no meio, ou nos objetos de apropriação, sequer na "ensinagem". Essa construção e reconstrução são muito mais marcadas pelo "e" que pelo "ou", denotando a complexidade desse fenômeno. As dificuldades de aprendizagem evidenciam não apenas um resultado insatisfatório, mas também as teias que o engendraram processualmente.

Tomando por base essa compreensão teórica, entendemos ser possível declinar princípios norteadores que podem resgatar a dimensão pedagógica no trabalho com as dificuldades de aprendizagem na sala de apoio.

No presente artigo, nossa discussão não recaiu sobre definições, nomenclaturas, classificações ou avaliações das dificuldades de aprendizagem. Consideramos a significação das dificuldades de aprendizagem para os alunos envolvidos diretamente com as salas de apoio, espaço oficial de trabalho com dificuldades de aprendizagem nas escolas estaduais no município de Londrina, onde o estudo se desenvolveu. Interessou-nos analisar as "significações de si" dos alunos ditos com dificuldades de aprendizagem, com queixas de erros recorrentes em situações de aprendizagem e que frequentam a sala de apoio.

\section{Dificuldades de aprendizagem - um olhar a partir da perspectiva teórica piagetiana}

Diferentes campos teóricos reconhecem a existência de elementos contextualmente articulados na aprendizagem do aluno e oferecem uma compreensão que supera a configuração de uma listagem de sintomas aparentes e impedidores das interações desses alunos com o conhecimento, como sinônimos de dificuldades de aprendizagem. Dentre os distintos modelos teóricos, 
Significações de si: sala de apoio como lugar destinado ao não saber na escola

como afirmamos, elegemos a perspectiva piagetiana, cujo modo de perceber as dificuldades de aprendizagem vai para além do que falta à criança, seus limites e impossibilidades (BECKER, 2008; DONGO-MONTOYA, 2009). Nessa compreensão, as ações e significações do sujeito, a riqueza dos procedimentos e processos construtivos, o contexto no qual o sujeito significa o real, dentre outros elementos são postos em relação de interdependência no estudo sobre o aprender. Orientados por esse pressuposto, as dificuldades de aprendizagem não podem ser analisadas apenas como pertencentes ao aluno e à sua família, mas também sugerem um amplo contexto a produzi-las (MACEDO, 1994).

A compreensão de fatores interatuantes nos processos de aprendizagem nos remete a uma rede de relações sistêmicas que favorecem a conectividade do aluno à escola. Dar conta das demandas escolares implica estar conectado, e estar conectado significa pertencer a uma rede que integra trocas e aprendizagens mútuas. Ao se considerar o princípio da complexidade, o conceito de interdependência de Piaget (1980) é esclarecedor quanto ao que vem a ser uma relação presente na constituição de um fenômeno amplo, múltiplo e complexo como a aprendizagem e as dificuldades decorrentes.

144 Sistemas interdependentes constituem a dialética construtiva. Tal compreensão nos auxilia no entendimento da condição inegável da complexidade e dinamismo próprios à mudança do indivíduo que se desenvolve, na condição de sujeito-autor do seu próprio desenvolvimento - teia no seio da qual o aprender se tece. Sob esse prisma, o conhecimento é concebido como um processo e não como um estado (resultado ou produto) e a escola, como um importante espaço (não apenas físico) para a construção desse conhecimento (PIAGET; GRÉCO, 1974). Essa complexidade é inerente à aprendizagem e pode auxiliar na compreensão das dificuldades de aprendizagem.

Macedo argumenta:

[...] dificuldades de aprendizagem devem ser vistas como problema de ordem complexa não importa se envolvam o sistema como um todo (isto é, as estruturas e relações que o constituem), uma classe ou grupo de alunos ou um caso individual (singular) (MACEDO, 2008, p. 2).

autor, em oposição ao que comumente é entendido pelo termo dificuldade de aprendizagem (os aspectos negativos e a ênfase ao que falta), 
faz alusão ao fato de que as dificuldades de aprendizagem, na perspectiva de Piaget, não são consideradas como algo negativo, uma vez que, nessa concepção teórica, o problema, o desafio, a dificuldade são extremamente importantes à construção do conhecimento. Prossegue Macedo:

Quem não aceita enfrentar dificuldades para realizar tarefas ou compreender problemas difíceis, porque novos, porque o conhecimento disponível sobre eles é insuficiente, não se desenvolve além dos limites atuais, fica refém de algo que não combina com a missão da escola (aprender) (MACEDO, 2008, p. 3).

Apropriarmo-nos dessa compreensão pode desencadear um novo olhar para o não aprender. As possibilidades e o desejo de aprender podem ser incentivados, dificultados ou interrompidos nas (inter e intra) interações do sujeito com o meio onde vive. Nessa ótica, o não aprender passa a atribuir significação à complexidade do processo na medida em que se apresenta como uma resposta insuficiente do aluno a uma exigência que não é apenas dele, mas também externa a ele. As dificuldades de aprendizagem evidenciam não apenas um processo insatisfatório do aluno, mas também de um contexto.

Na perspectiva piagetiana, para o desenvolvimento do indivíduo, supõe um sujeito ativo que constrói não apenas o saber, mas também os mecanismos e processos com os quais pode conhecer, mediante uma relação autônoma, espontânea e de autoria própria. Essa teoria aponta processos interacionais construtivos, na medida em que desloca o olhar das condições ideais de aluno, de professor, de programas instrucionais, para o processo de construção, de adaptação, de equilibração. $\bigcirc$ conceito de adaptação em Piaget vai para além da ideia de ajustamento ao meio, ou de superação de condições adversas do ambiente. Implica relações interdependentes, possivveis pelo processo de equilibração e de autoria do sujeito que aprende e que se desenvolve.

Piaget (1975, p. 40) entende a aprendizagem como "[...] um processo adaptativo que se desenvolve no tempo, em função de respostas dadas pelo sujeito a um conjunto de estímulos anteriores e atuais". Essa conceituação leva-nos a reconhecer uma peculiaridade na compreensão das dificuldades de aprendizagem: são passíveis a um processo de construção, uma vez que o processo de aprendizagem é adaptativo, ou seja, não está pronto e depende da equilibração. 
Significações de si: sala de apoio como lugar destinado ao não saber na escola

Ao conceber adaptação, o autor distingue adaptação-estado, da adaptação-processo. Teoriza Piaget (1975) que a adaptação-estado refere-se ao equilíbrio entre assimilações e acomodações, entretanto a principal forma de adaptação, a adaptação-processo, é aquela que permite descrever progressos do conhecimento, justamente porque vai além da "plasticidade" adaptativa do sujeito às demandas e às pressões do meio. Extingue-se a necessidade de deformar o real (assimilação) em função do próprio ponto de vista. Não há mais necessidade de a acomodação se moldar aos dados exteriores, passando a se constituir em uma experiência inteligente de fato (MONTANGERO; MAURICE-NAVILLE, 1998; GARCIA, 2010).

Por esta razão, entendemos que a tese da equilibração, da atividade construtiva do sujeito, das regulações ativas que o processo de sucessivas tomadas de consciência engendra, atendendo a necessidades internas de equilíbrio, pode apontar indicadores na compreensão das dificuldades de aprendizagem. Estão elas relacionadas à adaptação como estruturante das atividades internas do sujeito em relação de interdependência com o meio no qual está inserido (PIAGET 1975; 1977). Retomando a reflexão de Macedo (2008, p. 3), podemos afirmar que "[...] aprender, neste sentido, é enfrentar e 146 resolver problemas; dominar procedimentos, isto é, ações orientadas para um objetivo ou propósito".

As dificuldades de aprendizagem podem indicar desequilíbrios, perturbações ao sistema cognitivo. As contradições entre afirmações e negações provocam a necessidade de progresso, porque o sistema cognitivo se lança à busca incessante da eliminação das contradições ou do equilíbrio. Assim, podemos considerar que as manifestações de aprendizagem e de dificuldades de aprendizagem são conquistas do sujeito, estruturantes das relações entre os observáveis, regulações do sujeito durante o processo de construção do conhecimento.

Neste sentido, as dificuldades de aprendizagem não podem ser desconsideradas, desvalorizadas, reduzidas a um rótulo imposto ao sujeito. Não são externas ao processo e estão presentes no universo de significações no contexto de aprendizagem. Ao invés de pertencerem ao sujeito como uma marca que o desqualifica, que "explica" de forma reducionista o não aprender, as dificuldades de aprendizagem revelam a criação, a modificação, a estruturação, do mesmo modo que elas indicam estagnação, incompreensão, centração, predomínio das afirmações sobre as negações, ou seja, são 
reveladoras do movimento de constituição do sujeito aprendente, no sentido proativo do processo construtivo.

Posto isto, passamos a analisar o espaço oficializado para o trabalho com as dificuldades de aprendizagem nas escolas: as salas de apoio.

\section{Salas de apoio à aprendizagem - caracterização}

A Secretaria do Estado do Paraná (SEED) implantou, no ano de 2004, - Programa denominado Sala de Apoio à Aprendizagem. De acordo com a Resolução 371/2008, art. 1², a Secretaria da Educação do Estado do Paraná implantou as Salas de Apoio à Aprendizagem para atender aos alunos do $6^{\circ}$ ano $\left(5^{a}\right.$ série) do Ensino Fundamental que frequentam as escolas estaduais e apresentam dificuldades de aprendizagem com o objetivo de diminuir os índices de reprovação e evasão nesta série (PARANÁ, 2008).

Os documentos que instruíram e regulamentaram a criação das Salas de Apoio à Aprendizagem foram a Lei de Diretrizes e Bases da Educação Nacional (LDBEN) n 9394/96, o Parecer CNE n 04/98, a Deliberação n 007/99-CEE e a Resolução Secretarial n 371/2008. Segundo a instrução $n^{\circ}$ 022/2008, existem alguns critérios para a abertura e a organização das salas de apoio: destinam-se às disciplinas de Língua Portuguesa e Matemática, são oferecidas na proporção de uma sala de apoio para cada três turmas de $5^{a}$ série por escola, quatro horas semanais por disciplina, uma hora atividade para o professor e sua oferta deverá ser para, no máximo 15 alunos, em turno contrário no qual os alunos estão matriculados $\left(5^{a}\right.$ série) série (PARANÁ, 2008a).

objetivo principal das salas de apoio é o enfrentamento das dificuldades apresentadas pelos alunos com relação à aprendizagem de Língua Portuguesa - oralidade, leitura, escrita - e Matemática - formas espaciais e quantidades nas suas operações básicas e elementares.

\section{Método}

$\bigcirc$ presente estudo se orientou pelos parâmetros da pesquisa qualitativa, na modalidade de estudo descritivo-interpretativa. Essa modalidade de 
Significações de si: sala de apoio como lugar destinado ao não saber na escola

pesquisa permite não apenas a descrição das características de determinada população ou fenômeno, como o estabelecimento de relações entre variáveis, a problematização do objeto e a interpretação diante do corpo teórico adotado (YIN, 2005).

A pesquisa teve como participantes 52 alunos que frequentavam, no ano de 2010, $06^{\circ}$ ano do Ensino Fundamental e, no contraturno, a Sala de Apoio à Aprendizagem. Tinham idades compreendidas entre 11,3 meses e 14, 2 meses, oriundos de oito escolas da rede estadual de diferentes regiões da cidade de Londrina-PR. A coleta de dados foi feita durante oito horas semanais, por dois meses e como instrumentos de registro dos dados utilizamos um roteiro de entrevista semiestruturado, diário de campo e videogravação. Os procedimentos éticos de pesquisa foram adotados e o estudo foi aprovado pelo comitê de ética em pesquisa envolvendo seres humanos da Universidade Estadual de Londrina/HUHC com o nº07/09.

Considerando a natureza do estudo, os procedimentos de coleta de dados foram aplicados de modo semelhante em cada unidade escolar. A entrevista com os alunos foi realizada individualmente, retirando-os da aula na sala de apoio para participar da entrevista, retornando em seguida. A seleção dos

148 participantes adotou como critério de inclusão/exclusão, a participação na sala de apoio. Como instrumentos de coleta e de registro dos dados, utilizamos diário de campo, videogravação e o roteiro norteador da entrevista.

\section{Resultados e discussões}

\section{Caracterização geral dos participantes}

As unidades escolares investigadas revelaram semelhanças quanto ao modo como os alunos foram encaminhados para a sala de apoio. Nas primeiras semanas do ano letivo, as Salas de Apoio à Aprendizagem foram constituídas nas escolas de acordo com os encaminhamentos feitos pelos professores das salas regulares do $6^{\circ}$ ano, que identificaram, por meio do desempenho nas atividades escolares, os alunos com dificuldades de aprendizagem. Os alunos e respectivos pais foram avisados de que o aluno deveria frequentar a sala de apoio duas vezes na semana (4 aulas para o caso de uma 
disciplina, 8 aulas se houvesse necessidade nas duas disciplinas - Português e Matemática).

Significação dos Alunos sobre Dificuldades de Aprendizagem

Na análise das respostas dos participantes, pudemos encontrar três importantes significações: dificuldades de aprendizagem, noção de erro e percepção da sala de apoio. Denominamos, nessa leitura, "significações de si" à anunciação que fizeram os frequentadores da sala de apoio, participantes de nosso estudo.

Perguntamos a eles o que é dificuldade de aprendizagem, por ser este um termo recorrente na fala deles. Sabem que a razão de sua participação na sala de apoio é queixa de dificuldades de aprendizagem. Durante a conversa, perguntamos ainda que características um aluno precisa ter para que seja classificado como sendo um aluno que tem dificuldades de aprendizagem. É interessante observar que falam de si mesmos, inclusive empregando a primeira pessoa, e descrevem sua vivência na sala de apoio.

Organizamos as respostas de nossos sujeitos, alocadas nesse eixo, por sua ênfase em quatro categorias principais: falta de inteligência, comportamento inadequado, problemas orgânicos ou emocionais e problemas familiares. A tabela, a seguir, quantifica as categorias encontradas nas falas dos sujeitos. Considerando o elevado número de participantes do estudo e objetivando exemplificar o conjunto de respostas obtidas, optamos por apresentar três fragmentos de protocolo das entrevistas para cada uma das categorias. 


\section{Quadro 1}

Características do aluno com dificuldades de aprendizagem

\begin{tabular}{|c|c|c|}
\hline Categorias & $\begin{array}{l}\text { Quantidade } \\
\text { de Respostas }\end{array}$ & Exemplificação por meio dos Protocolos \\
\hline $\begin{array}{l}\text { Categoria } 1 . \\
\text { Falta de } \\
\text { inteligência }\end{array}$ & 23 & $\begin{array}{l}\text { "Não sou inteligente. Não sou bom de es- } \\
\text { tudos. Tipo assim: Não sou muito bom para } \\
\text { captar de uma vez, tem algumas pessoas } \\
\text { que estralou o dedo e já aprendeu." } \\
\text { "Enquanto os colegas compreendem e } \\
\text { sabem raciocinar, eu não sei por que não } \\
\text { sou esperto." } \\
\text { "Não consigo fazer contas, leitura, racioci- } \\
\text { nar porque a inteligência é curta." }\end{array}$ \\
\hline $\begin{array}{l}\text { Categoria } 2 . \\
\text { Comportamento } \\
\text { inadequado }\end{array}$ & 14 & $\begin{array}{l}\text { "Não consigo ficar quieto, sentado, prestan- } \\
\text { do atenção em coisas chatas"; } \\
\text { "não sou bom pra terminar primeiro. Sou } \\
\text { uma lesma que se arrasta e perturba todo } \\
\text { mundo. Sou um problemático. Todo mundo } \\
\text { reclama de mim, é isso." } \\
\text { "Sou um aluno que não tem disciplina. A } \\
\text { professora me chama brava a aula inteira". }\end{array}$ \\
\hline $\begin{array}{l}\text { Categoria } 3 . \\
\text { Problemas } \\
\text { orgânicos ou } \\
\text { emocionais }\end{array}$ & 8 & $\begin{array}{l}\text { "Sou um carinha meio pancada. Tipo assim: } \\
\text { todo nervoso, bolado... bem ferradinho. } \\
\text { Qualquer coisa... fico bravo, porque quem } \\
\text { tem dificuldade, tem problema na cabeça." } \\
\text { "É por causa de alguma doença que acabou } \\
\text { me afetando na escola." } \\
\text { "Eu tenho que tomar remédio porque tenho } \\
\text { algum problema, desses que tem que ir ao } \\
\text { médico de cabeça pra tratar. Alguns não } \\
\text { vão, mas tem alguma coisa na cabeça deles } \\
\text { por isso não aprendem." }\end{array}$ \\
\hline $\begin{array}{c}\text { Categoria } 4 . \\
\text { Problemas } \\
\text { familiares }\end{array}$ & 7 & $\begin{array}{l}\text { "Eu tenho problema em casa. Pai e mãe que } \\
\text { vira um inferno, bebe, fuma crack, essas coi- } \\
\text { sas." } \\
\text { "É que a minha casa é uma zona, não dá } \\
\text { pra estudar nada, daí não aprendo, não } \\
\text { faço tarefa, nem trabalhos." } \\
\text { "É porque a minha família não ajuda, só } \\
\text { atrapalha." }\end{array}$ \\
\hline
\end{tabular}

Fonte | Elaborado pelos autores 
Gostaríamos de ressaltar, nas respostas apresentadas pelos sujeitos, que, nas quatro categorias localizadas, o aluno chama para si e, no máximo, estende à sua família a causa do não aprender. Percebemos uma forte tendência entre os entrevistados de interpretar as dificuldades de aprendizagem como um problema pessoal, um impedimento que os constitui e avaliam que não há outra razão senão suas próprias impossibilidades a impedir que aprendam.

As respostas permitem inferir a existência de um discurso oculto do qual se apropriaram na trajetória escolar que os aponta como culpados e os responsabiliza pelo não aprender. A atribuição das inadequações no processo de aprendizagem a condições inatas ou ao ambiente familiar é muito frequente nos achados de pesquisas (VASCONCELOS; BELLOTTO, 2011 ).

No caso dos participantes de nosso estudo, é preocupante o fato de que são alunos frequentadores de um espaço oficializado para o trabalho com as dificuldades de aprendizagem e deveriam, por esta razão, sentirem-se conectados à escola, mas anunciam-se desvinculados, impossibilitados de apropriarem-se do saber oferecido por ela. Estes alunos se consideram pouco inteligentes, percebem suas famílias como inadequadas, consideram que thes falta controle dos próprios comportamentos, ou acreditam que carregam em si um problema orgânico, neurológico ou emocional impeditivo de interações saudáveis com o aprender.

Nossos dados demonstraram ainda que a condição incapacitante assumida por nossos sujeitos nas significações de si atingiu suas famílias. Atribuem a elas a condição faltosa na relação de apropriação do saber escolarizado. Collares e Moysés (1996) analisam a concepção de família que predomina no universo escolar. As autoras desvelam uma visão de família idealizada, que revela o desconhecimento da vida concreta das pessoas com as quais lidam. Acrescentam que "[...] ignorar as origens e obrigar transformações em um padrão totalmente idealizado, cumpre funções importantes no sistema social". E assinalam que "[...] os que não se ajustam à norma, por usufruírem de valores diferentes [...] ou, simplesmente por viverem um retrato distinto de família, passam a ser considerados, rotulados, como 'desajustados "' (COLLARES; MOYSÉS, 1996, p. 176).

Recorrer a Goffman (1988) e à conceituação de estigma nos permite compreender o discurso oculto e atuante na fala dos entrevistados. Embora não 
Significações de si: sala de apoio como lugar destinado ao não saber na escola

se trate de uma marca corporal indicativa de uma falha moral ou de capacidade da pessoa, revela uma "identidade social" dos alunos frequentadores da Sala de Apoio à Aprendizagem que lá estão porque são ditos com dificuldades de aprendizagem.

No caso de nossos participantes, nem mesmo o rendimento escolar é considerado nas indicações para a sala de apoio. São indicados por seus professores para a sala de apoio já nas primeiras semanas do ano letivo, sem que tenham passado por avaliações formais que denunciem baixo rendimento, dificuldades de compreensão, etc. Isso denota que há uma norma ou padrão que rege a classificação desses alunos e dela podem surgir os estereótipos revelados na fala dos alunos frequentadores desse espaço.

As expectativas normativas do processo de aprendizagem são transformadas em padrão de normalidade ou descritores de aluno ideal e, quando um aluno apresenta um processo de aprendizagem que destoa desse padrão imposto, os atributos depreciativos tomam o lugar da pessoa, do aluno, de sua família, do aprendente. A literatura que discute preconceito e estigmatização oferece respaldo à compreensão do danoso poder de incorporação do discurso estigmatizante pelos estigmatizados (ITANI, 1998; SCHILLING; 152 MYASHIRO, 2008).

Nas significações dos alunos sobre as dificuldades de aprendizagem, encontra-se a noção de erro. Nosso roteiro de entrevista estabeleceu identificar qual o significado do erro para o grupo de participantes. Para isto, perguntamos a eles o que é erro e como se sentiam quando erravam na sala de apoio. Agrupamos as respostas dos participantes, elegendo alguns temas predominantes nas respostas dadas, os quais são representados no gráfico e apresentamos alguns protocolos para exemplificá-los: sentimentos evocados por situações em que o erro está presente, erro e juízo moral e erro como desencadeador de conduta de afastamento, fuga ou evitação.

$\bigcirc$ gráfico a seguir anuncia a porcentagem encontrada por categoria, considerando $\mathrm{N}=52$ e aplicando-se regra de três simples. 
Gráfico | Representação das significações de erro

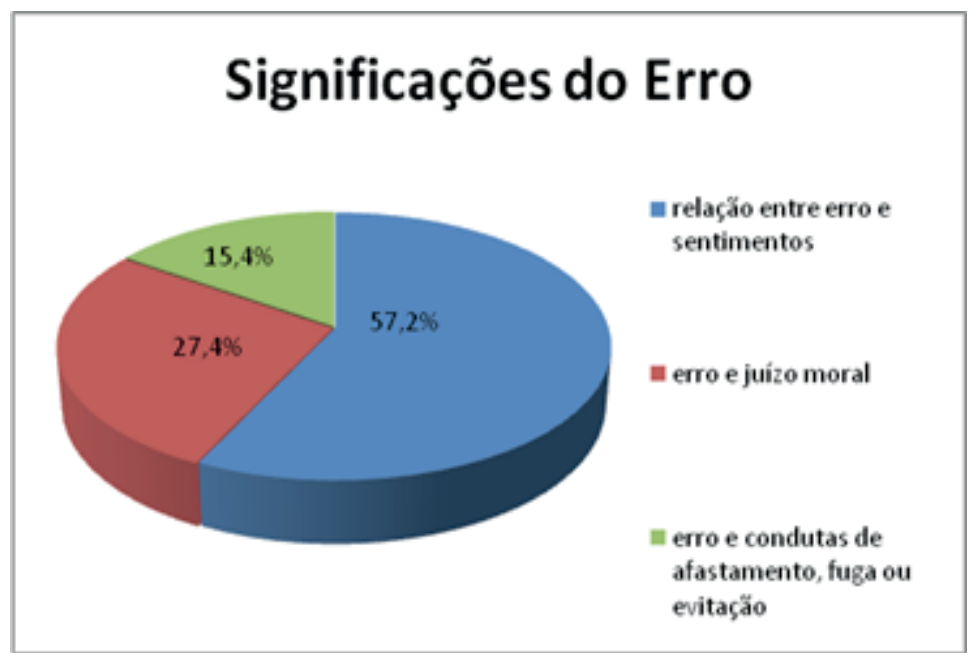

Fonte | Elaborado pelos autores

Sentimentos evocados por situações nas quais o erro está presente

Na abordagem teórica piagetiana, base de nossas considerações neste artigo, os afetos são compreendidos como preparadores das ações do sujeito, participando ativamente da percepção das situações vividas e do planejamento de suas reações ao meio. Dolle e Bellano (1999) consideram que a afetividade está implicada nas significações e, nestas últimas, as relações interindividuais têm um papel importante:

A afetividade, nas relações interindividuais, se alimenta unicamente do sentido e que é este quem a estrutura, desequilibra, equilibra e reequilibra. [...] Dito de outro modo, a afetividade em ato fala àquele que a recebe porque ela tem um sentido e informa sobre o estado daquele que o leva a falar, sobre suas intenções, seus julgamentos, sua disposição de espírito com relação ao destinatário, etc. (DOLLE; BELLANO, 1999, p. 120).

No ambiente escolar, o aluno experimenta vários tipos de afetos: sentimentos como o prazer da descoberta, a alegria da criação diante do objeto do conhecimento, a tristeza pelo erro na resolução das atividades, o senso de competência ou incompetência diante de sua produção, culpa, vergonha, 
Significações de si: sala de apoio como lugar destinado ao não saber na escola

dentre outros. Apresentamos alguns fragmentos de protocolo das entrevistas nos quais a fala dos participantes é elucidativa:

[...] errar é uma coisa ruim. Quando erro alguma conta é horrível. Me sinto mal quando erro. Dá vergonha de ter errado (A 1, 2010).

Errar é quando uma pessoa faz algo sem pensar. Fico nervosa quando erro e daí a professora grita e fico mais nervosa ainda e acabo errando de novo no mesmo lugar. O mais difícil foi superar uma vez que errei e fiquei com muita vergonha (A2, 2010).

Além dos sentimentos, a afetividade contempla elementos energéticos, os quais envolvem interesse, esforços, afetos das relações interindividuais, simpatias mútuas e sentimentos morais, que também estão presentes na sala de aula. Dito de outro modo, nas interações no cotidiano escolar, o sujeito é convidado, por meio da contradição de suas posições e questionamento de suas certezas, a (re) significar suas ações.

La Taille (1997), estudando a atribuição do sentimento de vergonha, faz uma relação entre esse sentimento e o desenvolvimento moral e demonstra 154 que, assim como o sentimento de culpa, a vergonha emerge cedo no contexto das relações humanas, mas se torna mais intensa e complexa na medida em que o desenvolvimento moral transcorre.

Nessa perspectiva, cabe questionar qual será a decorrência de sentimentos, se desmotivadores ou não, evocados por situações de erro do aluno na sala de aula. $O$ ajustamento realizado pelo sujeito, à medida que toma consciência de um engano, poderá percorrer caminhos totalmente racionais, com julgamentos adequados, mesmo numa situação desmotivadora? Ou ainda, em que a afetividade pode influenciar as interpretações da razão?

Piaget (1962; 1980), Sastre e Moreno (201 1), ao discorrerem sobre a aprendizagem humana, consideram importante olharmos para os afetos, visto que não se pode separar a atividade intelectual do funcionamento total do organismo. Em sua teoria, aponta que o desenvolvimento intelectual possui dois componentes, o cognitivo e o afetivo, articulados entre si, cujo desenvolvimento é continuamente solidário. A afetividade atua como "mola propulsora" da aprendizagem, uma vez que, sem afeto, não haveria interesse, nem necessidade, nem motivação e, consequentemente, perguntas ou problemas nunca seriam colocados e não haveria desenvolvimento da inteligência. $\bigcirc$ afeto é a 
energização da atividade intelectual, uma condição necessária para aquele que se coloca a conhecer.

\section{Erro e Juízo Moral}

Como fizemos no eixo anterior, antes de discutirmos a relação entre erro e juízo moral para os participantes do estudo, apresentamos um conjunto composto por exemplos de falas dos sujeitos extraídos da entrevista realizada.

[...] errar é quando não dá pra voltar atrás. É algo sem volta. Ou roubar ou trapacear. Ou brigar com um amigo. Dá vontade de chorar porque eu não entendo a matéria daí eu erro e daí a professora não tem paciência e então é mal isso (A3, 2010).

Errar é gesto de mal gosto e é igual errar uma questão da prova (A4, 2010).

Errar é roubar. Não cumprir a regra. Brigar, responder. Errar exercícios. Na sala de apoio é porque eu não sei resolver os exercícios (A5, 2010).

Para analisar a relação entre afetividade e inteligência, Piaget e Gréco (1974) discutem as concepções sobre o juízo moral em sua teoria. Normalmente, vemos a moral tornar-se o cenário propício para o confronto existente entre a razão e a afetividade. Vários exemplos na literatura destacam personagens lidando com situações conflituosas, nas quais há ou um predomínio da razão ou da afetividade.

Piaget, de acordo com La Taille (1997), vai além da ideia de confronto nessa relação e aponta considerações relevantes sobre como interagem estes dois aspectos no ser humano (cognição e afetividade). Os afetos movem a ação do sujeito e a razão identifica desejos, sentimentos variados a fim de obter êxito nas ações. Por isso, o autor considera problemático pensar "a razão contra a afetividade porque então se deveria, de alguma forma, dotar a razão de algum poder semelhante ao da afetividade" o que significaria considerar características móveis de energia também na razão (LA TAlLLE, 1997, p. 73).

A afetividade, para Piaget (1962), inicia-se pelos afetos perceptivos, que, no primeiro momento, encontram-se indiferenciados. Gradativamente, 
Significações de si: sala de apoio como lugar destinado ao não saber na escola

passarão a se diferenciar. A estrutura básica organizadora de nossa vida afetiva é formada por sentimentos como amor, raiva, medo, necessidades básicas e outras, resultantes de situações de fracasso ou sucesso, agradável ou desagradável. Macedo (2008, p. 48) aponta que o medo, assim como a raiva, ajuda o sujeito a "[...] fugir, afastar do que considera ameaçador ou doloroso. Em sua dimensão positiva, ele pode indicar cuidado e respeito [...]", mas, por outro lado, poderá diminuir ou até eliminar relações que proporcionaram esse sentimento. $\bigcirc$ amor pode produzir sentimentos' bons, como alegria, confiança, interesse, mas, em excesso, pode gerar dependência.

Sastre e Moreno (2002; 2005) analisam a importância de oportunizar aos alunos, por meio de práticas educativas, a distinção de diferentes emoções e estados de ânimo que experimentam e o reconhecimento desses afetos em si e nas pessoas com as quais convivem. Durante o processo de desenvolvimento da criança e com a ampliação gradativa da sua socialização, esses sentimentos passam a ser vivenciados de forma intencional e intuitiva. Os afetos tendem a ser transformados em norma, tendo em vista que a construção da regra é importante tarefa do processo de desenvolvimento.

Uma questão importante na construção da regra é a constituição da 156 vontade, por meio dela, a criança valoriza o que é superior e fraco, no lugar daquilo que é inferior, porém forte para o indivíduo. Claparède (1926) afirma:

Concluímos, pois: A vontade é o processo que tem por função reajustar a ação, momentaneamente suspensa pelo conflito de dois grupos de tendências, dando a supremacia às tendências superiores. Ou, mais resumidamente ainda: A vontade é o processo que resolve um problema de fim pela vitória das tendências superiores (CLAPARĖDE, 1926, p. 4-5).

Ao considerarmos a relação entre afetividade e aprendizagem, o estudo da vontade emerge indicando a importância da autorregulação. No desenvolvimento moral, o processo de passagem da heteronomia para a autonomia convida o sujeito ao reconhecimento da própria vontade. Permite que, gradativamente, sejam elaboradas as condições de enfrentamento que integram as dimensões afetivas e cognitivas indissociadamente.

As regras, em seu aspecto moral, constituem bom exemplo desse processo. Apresentam-se de forma heterônoma e a criança as entende como parte da tradição, por isto, inquestionáveis e sagradas (LA TAILLE, 1997). Somente 
no nível operatório formal, o sujeito poderá regular melhor seus afetos, controlar a vontade e expressar ideias de forma autônoma. Por essa compreensão processual, Piaget faz alusão ao papel funcional da afetividade na inteligência.

Na relação do sujeito com os objetos, com as pessoas e consigo mesmo, existe uma energia que direciona seu interesse para uma situação ou outra, e a essa energética corresponde uma ação cognitiva que organiza o funcionamento mental (ARANTES, 2003, p. 235).

As representações do erro como dimensões da afetividade no contexto escolar estão relacionadas ao nível de desenvolvimento do sujeito, bem como às concepções sobre "errar" em nossa sociedade. Estas, por sua vez, são dotadas de valores, crenças, regras e costumes imbricados a um padrão estabelecido de normalidade. Por isso, o sujeito, por ser um ser social, poderá caminhar na tentativa de cumprir o que está estabelecido como padrão, tendo clareza de que quem não cumpre é excluído, é tido como anormal IMACEDO, 1996). Ao erro, é atribuído o sentido de algo falso em oposição àquilo que é verdadeiro. A verdade é arbitrária e relativa e, em se tratando de crianças pequenas, verdade "[...] é aquilo que as pessoas que ela conhece e de quem gosta fazem ou dizem. 'Verdade' é aquilo que ela consegue fazer ou pensar, é o que obedece a sua intenção" (MACEDO, 1996, p. 194). Considerar o sentido atribuído ao erro na sala de apoio implica reconhecer os afetos e as normas como interdependentes e, portanto, importante espaço de reflexão.

\section{Erro como desencadeador de conduta de afastamento, fuga ou evitação}

Assim como nos itens anteriores, a relação entre erro e as condutas de afastamento e evitação são elucidativas das significações de erro para os participantes do estudo. Os dados nos permitem tecer considerações sobre o erro e o enfrentamento do conflito ou da tarefa proposta. Os sentimentos evocados nas situações de erro podem se relacionar ao sucesso ou insucesso na atividade e permitir atitude de enfrentamento dos conflitos, ou evocar a evitação.

Errar é uma coisa que faz você querer sumir. É uma coisa que não traz benefícios. É igual tirar nota ruim, reprovar. Dá vontade de 
Significações de si: sala de apoio como lugar destinado ao não saber na escola

nunca mais aparecer na escola. Na sala de apoio quando eu erro, o professor fica muito bravo comigo e grita muito. Fico malzão. Uma vez eu joguei um joguinho na sala de apoio e era de conta de vezes. Eu errei tanto que passei muita vergonha e não queria mais nem ver aquele jogo ou conta de vezes na minha frente (A6, 20101.

Errar é não acertar, vé. Ou você erra ou acerta. Se você acerta fica bem com todos. Se erra é melhor ficar na sua e fazer tudo sozinho porque ninguém vai te dar moral (A7, 2010).

A coragem e o medo podem indicar a manutenção do interesse na tarefa ou desafio proposto, promover o desenvolvimento do senso de competência e eficácia pessoal ou, ainda, indicar-the afastamento ou exclusão das possibilidades de realização do que é proposto (DOLLE; BELLANO, 1999).

$\bigcirc$ medo, nas tarefas escolares, parece indicar dependência, desinteresse, insegurança, raiva, conduta evitativa e, por fim, promover desistência da tarefa. O medo, a vergonha, a sensação de fracasso parecem fazer com que o sujeito saia, aos poucos, de cena, do ambiente de aprendizagem para aceitar, de modo passivo, o resultado de insucesso. Macedo (2008) nos con158 vida a refletir sobre a "morte do sujeito do conhecimento". Esclarece o autor que o medo mobiliza os sujeitos a criar estratégias não mais para aprender, mas para lidar com os sentimentos que o afastam do aprender. Entram em fuga daquilo que temem. Quando a tarefa evoca sentimentos positivos, estes funcionam como sustentadores do sujeito cognoscente no enfrentamento aos riscos inerentes às trajetórias do conhecimento.

Além de descobrir sobre o objeto, o sujeito, quando posto em atividade, está constantemente descobrindo sobre si: "o que sei", "o que não sei", "sou competente", "não sou competente", relacionando cognição a aspectos afetivos do próprio eu, como muito bem destacou Piaget (1994). Para o autor, a construção do conhecimento se dá de forma relacional com o conhecimento sobre o objeto, sobre si e sobre o outro. Na perspectiva teórica piagetiana, não basta "saber fazer", é preciso querer agir. Os afetos, os interesses movem a ação. A dimensão do afeto "permite o querer fazer". As significações são permeadas pela afetividade. 


\section{Sala de apoio, incompetência e punição}

Além de suas opiniões sobre o erro, investigamos os significados atribuídos pelos alunos à Sala de Apoio à Aprendizagem. Quando perguntamos por que foram escolhidos para a sala de apoio, enfatizaram o quanto são maus alunos, o quanto são burros, fracos, incompetentes para aprender. Analisemos algumas respostas dos participantes do nosso estudo:

Eu sou muito fraco e, aqui, eles ajudam a recuperar $(A 8,2010)$.

[...] moro com minhas tias, avós e mãe, acho que eles não incenti$\operatorname{vam}(A 9,2010)$.

[...] na hora (refere-se ao momento em que foi comunicada que iria para a sala de apoio), eu não senti nada, eu sabia que precisava vir e, mesmo que eu fosse bem, seria escolhida pra cá. A professora pegava no meu pé e eu era ruim mesmo (A10, 2010).

Essas falas são reveladoras de quanto o processo de culpa já atingiu esses alunos, fazendo com que incorporem o discurso de que têm um problema em si, ou em suas famílias. Ao investigar sobre como se percebem nas significações atribuídas pelo outro (alguém significativo) à participação deles, na sala de apoio, respondem:

[...] minha professora acha que sou bagunceira, namoradeira (A) 1, 2010).

[...] meus amigos tiram sarro, me chamam de burra $(A 12,2010)$.

[...] meus amigos acham que sou trouxa $(\mathrm{A} 13,2010)$.

[...] minha mãe acha que eu tenho que vir mesmo pra ficar mais inteligente $(A 14,2010)$.

[...] minha família acha que eu sou ruim $(A 15,2010)$.

[... eles (família) não gostam. Acham ruim eu estar no reforço já no começo do ano (A16, 2010).

[...] ela (professora) não acha nada, porque só grita e não conversa com os alunos $(A 17,2010)$. 
Significações de si: sala de apoio como lugar destinado ao não saber na escola

As significações acima descritas indicam que a sala de apoio é tida por eles (alunos frequentadores desse espaço) como um lugar para onde são enviados os que não têm competência para aprender ou porque merecem algum tipo de punição. Ao ter a chance de rever aquilo que não aprenderam e "desperdiçá-la", o estereótipo de mau aluno é reafirmado e, desse modo, a Sala de Apoio à Aprendizagem ratifica a segregação.

Os dados de nosso estudo salientam a força dos estereótipos e indicam o quanto permeiam todos os espaços, desde as políticas de implantação até o modo como crianças e familiares se veem participantes desse processo. Tais constatações, a nosso ver, colocam-se em dissonância com os objetivos para os quais um espaço de apoio à aprendizagem é instituído oficialmente.

\section{Considerações finais}

Pudemos discorrer sobre a sutil, mas eficiente inviabilização de um processo de restabelecimento das condições de aprendizagem em um espaço destinado ao trabalho com as dificuldades de aprendizagem no ambiente escolar. A partir do momento em que a rotulação e a segregação encontram lugar em detrimento da valorização de um processo de construção, constitui-se em um espaço de desencontros entre os caminhos trilhados pelo aluno na construção do conhecimento e os significados do aprender nesse contexto. Tais considerações nos remetem à necessidade de um percurso de trabalho a ser adotado nas Salas de Apoio à Aprendizagem que favoreça a ação autoestruturante do sujeito.

Valendo-nos do pressuposto teórico piagetiano adotado nesta pesquisa, a escola, em especial no trabalho com as dificuldades de aprendizagem, não pode prescindir de um ambiente problematizador que coloque o sujeito da aprendizagem em atividade construtiva. Situações problematizadoras, provocadoras de reflexão, análise dos próprios meios empregados e da tomada de consciência das próprias ações devem constituir a tônica de um projeto que visa oportunizar um ambiente específico de trabalho com as dificuldades escolares.

$\bigcirc$ erro precisa ser permitido em um espaço oficializado para $\bigcirc$ trabalho com o não aprender. Políticas públicas educacionais devem ser implementadas por meio de ações que avancem para além da constituição 
desses espaços nas escolas, que invistam, entretanto, na (re) significação do aprender/não aprender para os que deles participam. É importante pensar processos de formação proativos, objetivando oportunizar aos frequentadores da sala de apoio significações de pertencimento a esse espaço de intervenção escolar. No entendimento deste estudo, as ações na sala de apoio devem promover a conectividade do aluno à escola e desconstruir as ações segregadoras por meio das quais o aluno se vê desvinculado da escola, do aprender, do saber.

\section{Referências}

ARANTES, Valéria Amorin. Afetividade na escola: alternativas teóricas e práticas. São Paulo: Summus, 2003.

A 1. Entrevista oral. Londrina, Paraná, 04 out. 2010.

A2. Entrevista oral. Londrina, Paraná, 06 out. 2010.

A3. Entrevista oral. Londrina, Paraná, 06 out. 2010.

A4. Entrevista oral. Londrina, Paraná, 18 out. 2010.

A5. Entrevista oral. Londrina, Paraná, 20 out. 2010.

A6. Entrevista oral. Londrina, Paraná, 20 out. 2010.

A7. Entrevista oral. Londrina, Paraná, 25 out. 2010.

A8. Entrevista oral. Londrina, Paraná, 27 out. 2010.

A9. Entrevista oral. Londrina, Paraná, 03 nov. 2010.

A 10. Entrevista oral. Londrina, Paraná, 17 nov. 2010.

A 1 1. Entrevista oral. Londrina, Paraná, 17 nov. 2010.

A12. Entrevista oral. Londrina, Paraná, 22 nov. 2010.

A13. Entrevista oral. Londrina, Paraná, 22 nov. 2010.

A14. Entrevista oral. Londrina, Paraná, 24 nov. 2010.

A15. Entrevista oral. Londrina, Paraná, 24 nov. 2010.

A16. Entrevista oral. Londrina, Paraná, 29 nov. 2010. 
Significações de si: sala de apoio como lugar destinado ao não saber na escola

A 17. Entrevista oral. Londrina, Paraná, 29 nov. 2010.

BECKER, Fernando. Aprendizagem - concepções contraditórias, Marília, v. 1, n. 1, p. 53-74, 2008.

CLAPARÈDE, Édouard. A educação funcional. São Paulo: Companhia Editora Nacional, 1926.

COllARES, Cecília Azevedo Lima; MOYSÉS, Maria Aparecida Affonso. Preconceitos no cotidiano escolar: ensino e medicalização. Rio de Janeiro: Cortez, 1996.

DOLLE, Jean Marie.; BELLANO, Denis. Essas crianças que não aprendem: diagnósticos e terapias cognitivas. 4. ed. Petrópolis, RJ: Vozes, 1999.

DONGO-MONTOYA, Adrián Oscar. Teoria da aprendizagem na obra de Piaget. São Paulo: Editora da UNESP, 2009.

GARCIA, Heloisa Helena Genovese de Oliveira. Adolescentes em grupo: aprendendo a cooperar em oficinas de jogos. 2010. 275f. Tese (Doutorado em Psicologia) - Programa de Pós Graduação em Psicologia, Universidade de São Paulo, São Paulo, 2010.

GOFFMAN, Erving. Estigma: notas sobre a manipulação da identidade deteriorada. 4 ed. 162 Rio de Janeiro: Guanabara, 1988.

ITANI, Alice. Vivendo o preconceito em sala de aula. In: AQUINO, Julio Groppa. Diferenças e preconceito na escola: alternativas teóricas e práticas. São Paulo: Summus, 1998.

LA TAILLE, Ives de. O erro na perspectiva piagetiana. In: AQUINO, Júlio Groppa. Erro e fracasso na escola. São Paulo: Summus, 1997.

MACEDO, Lino de. O lugar dos erros nas leis ou nas regras. In: MACEDO, Lino de (Org.). Cinco estudos de educação moral. São Paulo: Casa do Psicólogo, 1996.

Ensaios construtivistas. São Paulo: Casa do Psicólogo, 1994.

Dificuldades de aprendizagem e gestão escolar. São Paulo: Instituto de Psicologia da Universidade de São Paulo e Secretaria de Educação do Estado de São Paulo, 2008.

MONTANGERO, Jaques; MAURICE-NAVILLE, Danielle. Piaget ou a inteligência em evolução: sinopse cronológica e vocabulário. Porto Alegre: Artmed, 1998.

PARANÁ. Secretaria do Estado de Educação. Resolução n. 371/2008. Diário Oficial do Paraná, Curitiba. 2008. Disponível em: do <http://www.dioe.pr.gov.br>. Acesso em: 14 jun. 2009. 
Secretaria do Estado da Educação. Instrução n 022/2008 - SUED/SEED. Critérios para a abertura da demanda de horas-aula, do suprimento e das atribuições dos profissionais das Salas de Apoio à Aprendizagem - $5^{a}$ série do Ensino Fundamental, da Rede Pública Estadual. 2008a. Disponível em: <http://www.diaadia.pr.gov.br/deb/arquivos/File/salas_de_apoio/instrucões/instrucao022.pdf>. Acesso em: 14 jun. 2009.

PIAGET, Jean. La Relación del afecto con la inteligencia en el desarrollo mental del nino. The Bulletin of Menninger Clinical, Paris, v. 26, p. 129-137, 1962.

A equilibração das estruturas cognitivas: problemas centrais do desenvolvimento. Rio de Janeiro: Zahar, 1975.

A tomada de consciência. São Paulo: Melhoramentos; EDUSP, 1977.

As formas elementares da dialética. São Paulo: Casa do Psicólogo, 1980.

O juízo moral na criança. São Paulo: Summus, 1994.

PIAGET, Jean; GRÉCO, Pierre. Aprendizagem e conhecimento. São Paulo: Freitas Bastos, 1974.

SASTRE, Genoveva; MORENO, Montserrat. Como construimos universos: amor cooperación y conflito. Barcelona: Gedisa, 2011.

Resolução de conflitos e aprendizagem emocional: gênero e transversalidade. São Paulo: Moderna, 2002.

Conflitos e emoções: uma aprendizagem necessária. In: VINYAMATA, Eduard (Org.). Aprender a partir do conflito: conflitologia e educação. Porto Alegre: Artmed, 2005.

SCHILLING, Flávia.; MIYASHIRO, Sandra. Galdino. Como incluir? $\bigcirc$ debate sobre o preconceito e o estigma na atualidade. Educação e Pesquisa, São Paulo, v. 34, n. 2, ago. 2008. Disponivel em: <http://www.scielo.br/scielo.php?script=sci_arttexł\&pid=S1517$-97022008000200003 \&$ lng=pt\&nrm=iso>. Acesso em: 17 ago. 2011.

VASCONCELOS, Mário Sérgio; BELLOTO, Maria Elvira. Um estudo comparativo sobre a indisciplina escolar: representações de alunos e professores do ensino fundamental e médio. In: CONGRESSO DE PESQUISAS EM PSICOLOGIA E EDUCAÇÃO MORAL, 2., 2011 , Anais... São Paulo: Campinas, 2011.

YIN, Robert K. Estudo de caso: planejamento e métodos. Tradução Daniel Grassi. 3. ed. Porto Alegre: Bookman, 2005. 
Profa. Dra. Luciane Guimarães Batistella Bianchini

Profa. Convidada curso de Psicopedagogia Universidade Estadual de Londrina

Departamento de Psicologia Grupo de Pesquisa Epistemologia e Psicologia: processos e contextos de desenvolvimento humano E-mail | luannbi@hotmail.com

Profa. Dra. Francismara Neves de Oliveira Universidade Estadual de Londrina | UEL Departamento de Educação Coordenadora dos Grupos de pesquisa | Ensinar e Aprender: significações produzidas por gestores educacionais, professores e alunos envolvidos em programa de apoio à aprendizagem escolar 164 ensino de Psicologia da educação nos cursos de formação de professores: Pedagogia e demais licenciaturas da universidade Estadual de Londrina E-mail | francismara@uel.br

Prof. Dr. Livre-Docente Mario Sérgio Vasconcelos Universidade Estadual Paulista | UNESP | Campus Assis

Departamento de Psicologia Líder do Grupo de Pesquisa Epistemologia e Psicologia: processos e contextos de desenvolvimento humano E-mail | vascon@assis.unesp.br

Recebido 3 abr. 2014 Aceito 22 jul. 2014 